\title{
Fuel Metabolism Following 3 Days on a Carbohydrate-Free Diet vs. 3 Days of Fasting in Men with Type 2 Diabetes: A Randomized Controlled Crossover Trial
}

\author{
Nuttall $\mathrm{FQ}^{* 1,2}$, Almokayyad $\mathrm{RM}^{1,2}$ and Gannon $\mathrm{MC}^{1,2,3}$
}

${ }^{1}$ Section of Endocrinology, Metabolism \& Nutrition, and the Metabolic Research Laboratory (111G), Minneapolis VA Health Care System, Minneapolis, MN, USA

${ }^{2}$ Department of Medicine, Division of Diabetes, Endocrinology and Metabolism, University of Minnesota, Minneapolis, MN, USA

${ }^{3}$ Department of Food Science \& Nutrition, University of Minnesota, 1334 Eckles Avenue, St. Paul, MN, USA

${ }^{*}$ Corresponding author: Nuttall FQ, Section of Endocrinology, Metabolism \& Nutrition, and the Metabolic Research Laboratory (111G), Minneapolis VA Health Care System, Minneapolis, MN, USA, Department of Medicine, Division of Diabetes, Endocrinology and Metabolism, University of Minnesota, Minneapolis, MN, USA, Tel: 1-612-467-4424, E-mail: nutta001@umn.edu

Citation: Nuttall FQ, Almokayyad RM, Gannon MC (2018) Fuel Metabolism Following 3 Days on a CarbohydrateFree Diet vs. 3 Days of Fasting in Men with Type 2 Diabetes: A Randomized Controlled Crossover Trial. J Nutr Health Sci 5(2): 204. doi: 10.15744/2393-9060.5.204

Received Date: March 20, 2018 Accepted Date: April 28, 2018 Published Date: May 02, 2018

\begin{abstract}
Background: A 72-h fast results in a rapid decrease in circulating glucose to a lower level without a change in non-water body mass. Several metabolic adjustments are necessary. A nutrient-sufficient, carbohydrate $(\mathrm{CHO})$-free diet also has been reported to result in a decrease in glucose, and similar metabolic perturbations. However, direct comparisons are not available in subjects without, or with, type 2 diabetes (T2DM).

Objective: We are interested in the effect of variations in the diet on human physiology and metabolism in subjects with and without T2DM. Recently we have used two different approaches to maximally eliminate carbohydrate from the diet: a carbohydrate-free (CHOfree) diet and fasting. Our overall objective has been to compare the results when the metabolic fuel being oxidized is largely fat, without a significant loss of lean body mass.

Design: Using a crossover design, comparisons between a 72-h fast and ingestion of a CHO-free diet over $72 \mathrm{~h}$ were made in $7 \mathrm{male}$ subjects with T2DM. Data also were compared to a baseline standard diet.

Results: Fasting resulted in a greater and more rapid weight loss than a CHO-free diet. Resting metabolic rate and fuel mix being oxidized were similar. Glucose/glycogen utilization, based on $\mathrm{CHO}$ oxidation, was similar between the two, but much greater than reported in subjects without diabetes. Calculated protein metabolism rates were similar.

Conclusions and Significance: In subjects with T2DM, metabolic adaptations to a CHO-free diet and a $72 \mathrm{~h}$ fast generally are similar. Both interventions result in a major decrease in circulating glucose concentration. Some, though not all, results are similar to those reported in subjects without diabetes. A decreased circulating glucose concentration and/or its rate of metabolism likely regulate these adaptations, which occur at a higher fasting glucose concentration in subjects with T2DM. The adaptation also spares hydrolysis of endogenous proteins.
\end{abstract}

Keywords: Weight Loss; High Fat Diet; Metabolic Rate; Glycogen; Fuel Oxidation

List of abbreviations: BMI: Body Mass Index; CHO: Carbohydrate; h: hour(s); IRB: Internal Review Board; IV: Intravenous; N/A: Not Applicable; nRQ: non-Protein RQ; RMR: Resting Metabolic Rate; RQ: Respiratory Quotient $\left(\mathrm{CO}_{2} / \mathrm{O}_{2}\right)$; SDTU: Special Diagnostic \& Treatment Unit (Similar to a Clinical Research Center); SEM: Standard Error of the Mean; T2DM: Type 2 Diabetes Mellitus; VistA: Veterans Health Information Systems and Architecture

\section{Introduction}

Our laboratory is interested in the effect of variations in the diet on human physiology and metabolism in subjects with and without type 2 diabetes (T2DM). We are particularly interested in determining several factors related to fuel metabolism. 
Recently we have used two different approaches to maximally eliminate carbohydrate from the diet: a carbohydrate-free (CHOfree) diet and fasting. The metabolic effects of both have been compared in subjects with T2DM. Our overall objective has been to compare the results when the metabolic fuel being oxidized is largely fat, without a significant loss of lean body mass. Seventy-two hours of fasting is a time period over which a loss in non-water body mass is minimal [1]. Data from a 72-h fast were compared to 72-h macronutrient-sufficient, no carbohydrate, high fat diet in men with T2DM.

In the present report, weight changes, resting metabolic rate (RMR), plasma urea nitrogen, thyroid hormones, fuel oxidation, urine sodium, potassium, calcium, creatinine and urea nitrogen data are provided and discussed. The 24-hr glucose, insulin and glucagon responses [2] as well as the ghrelin and leptin responses [3] from these same subjects have been published.

\section{Materials and Methods}

\section{Design and Setting}

This is a randomized, crossover study design with a four-week washout period. On one occasion seven male subjects received a calorie-sufficient, $\mathrm{CHO}$-free diet for $72 \mathrm{~h}$ consisting of $<3 \%$ carbohydrate, $15 \%$ protein, $\sim 85 \%$ fat (Table 1 ). On another occasion, all subjects starved for $72 \mathrm{~h}$. This was preceded by a standard diet consisting of 55\% carbohydrate, $15 \%$ protein, $30 \%$ fat. Recruitment began in June of 2009; follow-up was completed in June of 2010.

\begin{tabular}{|c|c|}
\hline \multicolumn{2}{|r|}{ Day 1} \\
\hline Breakfast & $\begin{array}{l}\text { Scrambled eggs (with butter, heavy cream, cheese), } \\
\text { Fried salt pork }\end{array}$ \\
\hline Lunch & $\begin{array}{c}\text { Lettuce salad with cheese, cooked egg, ham, turkey, } \\
\text { Ranch dressing } \\
\text { Diet gelatin with whipped topping }\end{array}$ \\
\hline Dinner & $\begin{array}{l}\text { Ground beef with butter, chili seasoning } \\
\text { Cooked asparagus with Hollandaise sauce } \\
\text { Diet gelatin with whipped topping }\end{array}$ \\
\hline \multicolumn{2}{|r|}{ Day 2} \\
\hline Breakfast & $\begin{array}{l}\text { Scrambled eggs (with butter, heavy cream, cheese) } \\
\text { Fried salt pork }\end{array}$ \\
\hline Lunch & $\begin{array}{l}\text { Egg salad on lettuce leaf (eggs, mayo, green onion, dill pickle) } \\
\text { Diet Gelatin with whipped topping }\end{array}$ \\
\hline Dinner & $\begin{array}{l}\text { Polish sausage with cheese } \\
\text { Cottage cheese with } 1000 \text { island dressing } \\
\text { Lettuce salad with Caesar dressing, Parmesan cheese } \\
\text { Broccoli with Hollandaise sauce }\end{array}$ \\
\hline \multicolumn{2}{|r|}{ Day 3} \\
\hline Breakfast & $\begin{array}{l}\text { Fried eggs in butter } \\
\text { Sausage links } \\
\text { Tomato juice }\end{array}$ \\
\hline Lunch & $\begin{array}{c}\text { Tuna salad on lettuce leaf (tuna, mayo, celery, green onion, Sun- } \\
\text { flower seeds) } \\
\text { Diet gelatin with whipped topping }\end{array}$ \\
\hline Dinner & $\begin{array}{c}\text { Beef frankfurters } \\
\text { Lettuce salad with tomato and Blue Cheese dressing } \\
\text { Dill pickle } \\
\text { Mousse }\end{array}$ \\
\hline
\end{tabular}

${ }^{*}$ Adjusted as necessary to provide required calories for each individual, keeping the macronutrient content at $\sim 15 \%$ protein, $85 \%$ fat

Table 1: Foods for Carbohydrate-Free Diet*

Each subject was provided with a standardized dinner (55\% CHO, 15\% protein, and 30\% fat), to be ingested at home at $1800 \mathrm{~h}$ the day before admission. Thereafter, only water was allowed until admission to our clinical research unit (Special Diagnostic and Treatment Unit, SDTU) the next morning.

Subjects reported to the SDTU at $0700 \mathrm{~h}$. An indwelling IV catheter was inserted; blood samples were obtained at 0730,0745 and $0800 \mathrm{~h}$ for baseline determinations. Subjects received a standard breakfast, lunch and dinner at $0800,1200 \mathrm{and} 1800 \mathrm{~h}$, respectively. Blood samples were obtained every 15 minutes after each meal for the first h, every 30 minutes after the second and third $h$ and hourly after that until the next meal or until 0800 the next morning. Urine was collected over $24 \mathrm{~h}$. This represented day 1 of the study (control). 
On the second day, subjects were asked to starve for $72 \mathrm{~h}$, or were provided with the carbohydrate-free meals at 0800,1200 and $1800 \mathrm{~h}$ each day during the $72 \mathrm{~h}$. This represented days 2-5. Randomization occurred according to enrollment as follows: Subjects 1, 3, 5, and 7 fasted first; subjects 2, 4 and 6, received the $\mathrm{CHO}$-free diet first. A list of representative foods for the CHO-free diet is shown in Table 1. All 7 subjects completed both arms of the study without harm or unintended effects.

Ingestion of water was encouraged. Black coffee, tea without sugar or cream, and calorie-free beverages were allowed. Activity was limited to quiet diversions such as reading or watching TV. Blood samples were obtained during the first and last $24 \mathrm{~h}$ of the 72 -h intervention. Urine also was collected during the first and last $24 \mathrm{~h}$ as well. The subjects were under supervision the entire time.

Weight and blood pressure was determined daily in the AM, as was indirect calorimetry.

\section{Participants}

All subjects met the American Diabetes Association criteria for the diagnosis of type 2 diabetes [4]. Patient characteristics have been published previously [2]. Briefly, the mean age was 60 years (range 49-72); mean BMI was $31 \pm 2 \mathrm{~kg} / \mathrm{m}^{2}$ (range 25-38). Written informed consent was obtained from all subjects. The study was approved by the Internal Review Board (IRB), which also serves as the Ethics Committee, Department of Veterans Affairs, Minneapolis VA Health Care System and registered at ClinicalTrials. gov: NCT01469104.

\section{Assays}

Weight was determined on a digital scale (Scalitronix, White Plains, NY) in pajamas; blood pressure was determined using an automatic Dinemap Instrument (Critikon/Mediq, Pennsauken, NJ); indirect calorimetry (RMR and non-protein respiratory quotient (nRQ) was determined using a Medgraphics CPX Express apparatus (Medical Graphics Corp, St. Paul, MN), at $0800 \mathrm{~h}$ and over a 30-minute period.

Serum/plasma/urine data: creatinine, $\mathrm{TSH}, \mathrm{T}_{4}, \mathrm{~T}_{3}$, sodium, potassium, calcium, urea nitrogen and glucose were determined by an automated method on an Abbott Architect ci 8200 analyzer (Abbott Park, IL).

Plasma was analyzed for urea nitrogen over two 24-h periods (from 0800 on day 1 and 0800 on day 4). Some blood samples were not available during the overnight $\mathrm{h}$ for one subject while ingesting the $\mathrm{CHO}$-free diet. Therefore, that complete data set for the plasma urea nitrogen 24 -h profiles is presented for 6 subjects.

Dietary content of protein, fat and carbohydrate was estimated using diet analysis modules "Nutritionist Pro" (Axxya Systems LLC, Stafford, TX,) and "VistA" (Veterans Health Information Systems and Architecture; Department of Veterans Affairs, Veterans Health Administration, US Government). Both are based on United States Department of Agriculture (USDA) databases.

\section{Calculations}

The quantification of the carbohydrate (glucose) being oxidized was calculated based on the indirect calorimetry data. In the post-absorptive state, i.e., 14 h overnight without food, it was assumed that the glucose utilized came from endogenous sources (glycogen metabolism and gluconeogenesis) [5]. Two quantification methods were used. In the first, the fraction of energy utilization due to carbohydrate was determined using the nRQ data. In the second, quantitative excretion of potassium was used. During glycogenolysis in the liver, release of an amount of intracellular water containing $0.45 \mathrm{mmoles}$ of potassium/g of glycogen has been reported [6,7]. This potassium enters the circulation, and in an equilibrium state, would be excreted in the urine. Thus, we have used the quantity of potassium in the urine as a surrogate for net glycogen/glucose utilization as fuel.

The caloric value of glycogen is $4.1 \mathrm{Kcal} / \mathrm{g}$ compared to glucose which is $3.7 \mathrm{Kcal} / \mathrm{g}$ [8]. Thus, the amount of glucose contributed from glycogen is increased by $11 \%$.

Non-protein fuel oxidation was determined from published tables based on nRQ [9]. Protein fuel oxidation was calculated based on the 24-h urinary urea nitrogen excretion [10].

Protein metabolized generally is calculated by quantifying the total daily nitrogen lost. Urine urea nitrogen excretion makes up the great bulk, but small amounts are lost in the feces and from skin desquamation. In our study only the urinary urea nitrogen excretion was quantified and used to calculate protein metabolism ( $1 \mathrm{~g} \mathrm{~N}=6.25 \mathrm{~g}$ protein) [8].

\section{Area Determination}

The net and total integrated 24-h area responses were calculated with a computer program based on the trapezoid rule [11].

\section{Statistics}

Statistics were determined with Prism 4 software by Graphpad (LaJolla, CA) using paired Student's t-test. A p-value less than 0.05 was the criterion for significance. Data are presented as the mean \pm SEM. 


\section{Results}

\section{Body Weight}

The mean initial body weight was $97 \mathrm{~kg}$ and $96 \mathrm{~kg}$ at the beginning of the $\mathrm{CHO}$-free and fasting arms, respectively, indicating stability of the body weight over $\sim 5$ weeks. The mean body weight decreased from 97 to $95 \mathrm{~kg}$ after ingesting a carbohydrate-free diet for $72 \mathrm{~h}[2]$. The weight loss was essentially linear.

During fasting, the mean body weight decreased from 96 to $93 \mathrm{~kg} 72 \mathrm{~h}$ later. In contrast to the linear weight loss with the CHO-free diet, the majority of the weight loss occurred within the first $24 \mathrm{~h}$ of fasting (Table 2).

\begin{tabular}{|c|c|c|c|c|c|}
\hline CHO-Free & DAY $\mathbf{1}^{* *}$ & DAY 2 & DAY 3 & DAY 4 & DAY 5 \\
\hline & $\begin{array}{c}\text { Standard } \\
\text { Diet }\end{array}$ & $\begin{array}{c}\text { Start of CHO- } \\
\text { free }\end{array}$ & $\begin{array}{c}\text { 24 Hours } \\
\text { CHO-free }\end{array}$ & $\begin{array}{c}\text { 48 Hours } \\
\text { CHO-free }\end{array}$ & $\begin{array}{c}\text { 72 Hours } \\
\text { CHO-free }\end{array}$ \\
\hline Caloric Intake (Kcal/day) & $2464 \pm 126$ & $2436 \pm 116$ & $2436 \pm 116$ & $2436 \pm 116$ & N/A \\
\hline Weight (kg) & $96.7 \pm 6$ & $96.7 \pm 6$ & $96.2 \pm 6$ & $95.7 \pm 6$ & $95.3 \pm 6^{+5}$ \\
\hline Pulse (BPM) & $65 \pm 3$ & $64 \pm 2$ & $65 \pm 4$ & $66 \pm 4$ & $67 \pm 6$ \\
\hline BP/S (mmHg) & $130 \pm 7$ & $126 \pm 6$ & $123 \pm 6$ & $123 \pm 6$ & $120 \pm 2$ \\
\hline BP/D (mmHg) & $79 \pm 4$ & $73 \pm 2$ & $72 \pm 3$ & $71 \pm 2$ & $73 \pm 2^{\varsigma}$ \\
\hline RMR (Kcal/day) & $1803 \pm 133$ & $1867 \pm 154$ & $1829 \pm 110$ & $1701 \pm 68$ & $1661 \pm 65$ \\
\hline nRQ & $0.85 \pm 0.01$ & $0.84 \pm 0.02$ & $0.80 \pm 0.01$ & $0.80 \pm 0.01$ & $0.79 \pm 0.01$ \\
\hline \% CHO Oxidized & 50.7 & 47.2 & 33.4 & 33.4 & 29.9 \\
\hline \% Fat Oxidized & 49.3 & 52.8 & 66.6 & 66.6 & 70.1 \\
\hline Grams glucose & & 238 & & & 134 \\
\hline Grams glucose & & 249 & & & 165 \\
\hline
\end{tabular}

\begin{tabular}{|c|c|c|c|c|c|}
\hline Fasting & DAY 1 & DAY 2 & DAY 3 & DAY 4 & DAY 5 \\
\hline & $\begin{array}{c}\text { Standard } \\
\text { Diet }\end{array}$ & Start of Fast & $\begin{array}{c}\text { 24 Hours } \\
\text { Post fast }\end{array}$ & $\begin{array}{c}\text { 48 Hours } \\
\text { Post fast }\end{array}$ & $\begin{array}{c}\mathbf{7 2} \text { Hours } \\
\text { Post fast }\end{array}$ \\
\hline Caloric Intake (Kcal/day) & $2464 \pm 126$ & 0 & 0 & 0 & N/A \\
\hline Weight (kg) & $96.2 \pm 6$ & $96.2 \pm 6$ & $94.4 \pm 6$ & $94.0 \pm 6$ & $93.1 \pm 6^{+5}$ \\
\hline Pulse (BPM) & $68 \pm 4$ & $67 \pm 3$ & $69 \pm 5$ & $73 \pm 6$ & $73 \pm 5$ \\
\hline BP/S (mmHg) & $136 \pm 8$ & $121 \pm 4$ & $122 \pm 4$ & $122 \pm 8$ & $113 \pm 3$ \\
\hline BP/D (mmHg) & $79 \pm 3$ & $74 \pm 2$ & $73 \pm 2$ & $74 \pm 3$ & $68 \pm 2^{+5}$ \\
\hline RMR (Kcal/day) & $1724 \pm 112$ & $1866 \pm 76$ & $1661 \pm 107$ & $1609 \pm 126$ & $1572 \pm 101$ \\
\hline nRQ & $0.82 \pm 0.02$ & $0.85 \pm 0.01$ & $0.82 \pm 0.01$ & $0.79 \pm 0.01$ & $0.78 \pm 0.02$ \\
\hline \% CHO Oxidized & 40.3 & 50.7 & 40.3 & 29.9 & 26.3 \\
\hline \% Fat Oxidized & 59.7 & 49.3 & 59.7 & 70.1 & 73.7 \\
\hline Grams glucose & & 256 & & & 112 \\
\hline Grams glucose & & 224 & & & 146 \\
\hline
\end{tabular}

Values are means \pm SEM; ${ }^{*}$ Standard Diet=Control $(55 \%$ CHO, $15 \%$ protein, $30 \%$ fat $)$

${ }^{*}$ Day 1 and Day 5 weight published previously [2].

$+=\mathrm{P}<0.05$ Day 5 vs Day $2 ; \S=\mathrm{P}<0.05$ CHO-free day 5 vs. Fasting day 5

${ }^{1}$ Calculated from RMR \& nRQ

${ }^{2}$ Calculated from Urine Potassium

Abbreviations: $\mathrm{kg}=\mathrm{kilograms}$; $\mathrm{BPM}=$ beats per minute; $\mathrm{mmHg}=$ millimeters of mercury; $\mathrm{BP} / \mathrm{S}=$ blood pressure/systolic; $\mathrm{BP} /$

$\mathrm{D}=$ blood pressure diastolic; $\mathrm{Kcal} /$ day=kilocalories/day; $\mathrm{nRQ}=$ non-protein respiratory quotient; $\mathrm{RMR}=$ resting metabolic rate; $\mathrm{CHO}=$ carbohydrate

Note: That the data were obtained at $0800 \mathrm{hr}$. and thus are representative of the caloric intake from the previous day.

Table 2: Physiologic Data $(\mathrm{n}=7)$

\section{Blood Pressure}

The CHO-free diet, as well as fasting, resulted in a small decrease in blood pressure. However, only the decrease in diastolic pressure when the subjects had fasted was significant (Table 2).

\section{Calculated Food Energy Intake}

The mean calculated food energy intake when the subjects ingested the standard diet on day one was $2464 \mathrm{Kcal} / 24 \mathrm{~h}$ for both arms of the study. When ingesting the CHO-free diet it was $2436 \mathrm{Kcal} / 24 \mathrm{~h}$ (Table 2). 


\section{Indirect Calorimetry: Resting Metabolic Rate (RMR)}

The calculated RMR decreased from $1867 \mathrm{Kcal} /$ day at $0800 \mathrm{hr}$ on the morning of the first day of the CHO-free diet (day 2) to $1661 \mathrm{Kcal} /$ day following $72 \mathrm{~h}$ of the $\mathrm{CHO}$-free meals $(\Delta=-206 \mathrm{Kcal} /$ day). The average RMR for days $3-5 \mathrm{was} 1730 \mathrm{Kcal} /$ day. The calculated mean daily caloric intake was $2436 \mathrm{Kcal} /$ day. Thus the average excess caloric intake over RMR was $706 \mathrm{Kcal} / \mathrm{day}(29 \%)$ (Table 2).

On the first day of the fast (day 2), the calculated RMR was $1866 \mathrm{Kcal} /$ day. Following $72 \mathrm{hrs}$ of fasting, it decreased to $1572 \mathrm{Kcal} /$ day $(\Delta=-294 \mathrm{Kcal} /$ day). The average RMR for days 3-5 was $1614 \mathrm{Kcal} /$ day, and nearly all of the decrease occurred on the first day.

\section{Non-Protein Respiratory Quotient (nRQ)}

The initial mean nRQs were 0.84 on the first day of the CHO-free diet and 0.85 when fasting. The non-protein fuel mix being oxidized based on published tables was $47 \%$ carbohydrate, $53 \%$ fat for the $\mathrm{CHO}$-free diet and $51 \%$ carbohydrate, $49 \%$ fat with fasting [9]. The nRQ subsequently decreased to 0.79 at the end of the 72 -hr CHO-free diet and 0.78 with fasting. At this time the calculated non-protein fuel mix being oxidized was 30\% carbohydrate, $70 \%$ fat with the CHO-free diet and $26 \%$ carbohydrate, $74 \%$ fat with fasting. Thus, the nRQ data were similar whether the subjects fasted or ingested the CHO-free diet (Table 2).

\section{Protein Metabolism}

Plasma Urea Nitrogen (Figure 1): The overnight $0800 \mathrm{~h}$ fasting plasma urea nitrogen concentrations were similar for the Control pre $\mathrm{CHO}$-free diet and the Control pre fasting arms of the study, 6.78 and $6.07 \mathrm{mMol} / \mathrm{L}$, respectively. With the $\mathrm{CHO}$-free diet or with fasting they were identical, $6.07 \mathrm{mMol} / \mathrm{L}$. During the subsequent $24 \mathrm{~h}$ there was little change in concentration under any of the conditions. The net and total 24-h integrated area responses also were similar.
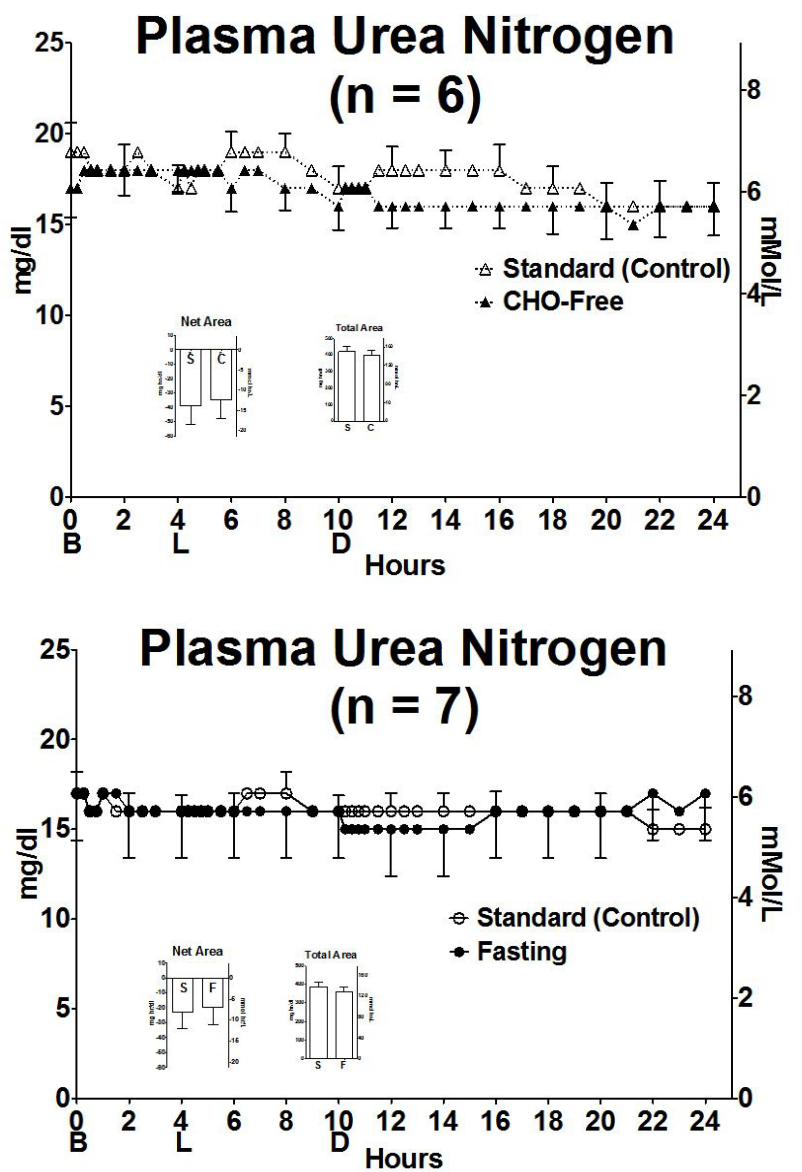

\footnotetext{
Top: ( $n=6)$ Mean \pm standard error of the mean (SEM) while ingesting the standard diet (i.e., control-open triangles) and for the last 24 hours (hours 48-72) of ingesting a CHO-free diet (closed triangles)

Bottom: ( $n=7)$ Mean \pm SEM while ingesting the standard diet (i.e., control-open circles) and for the last 24 hours (hours 48-72) of fasting (closed circles).

X-axis: 0 indicates 0800 hr. B, L, D indicate breakfast, lunch, and dinner meal times.

Y Axis: Left - concentration in English units, Right - concentration in Scientific Units

Inserts: Net Area represents the mean \pm SEM integrated 24-hr area response, using the overnight fasting concentration as baseline.

Total Area represents the mean \pm SEM integrated 24 -hr area response, using zero as baseline.

$\mathrm{S}=$ Standard diet (control), $\mathrm{C}=\mathrm{CHO}$-free diet, $\mathrm{F}=$ Fasting

Figure 1: Plasma Urea Nitrogen. Twenty-four hour plasma urea nitrogen responses.
} 
Urine Urea Nitrogen (Table 3): The initial 24 h quantitative urine urea nitrogen excretions also were similar. They decreased only modestly with ingestion of the $\mathrm{CHO}$-free diet or with fasting. The decrease was identical in both arms of the study (1.6 g), however, significant only with fasting.

\begin{tabular}{|c|c|c|c|c|c|c|}
\hline \multirow[b]{2}{*}{ Urine } & \multicolumn{6}{|c|}{ Meals } \\
\hline & $\begin{array}{l}\text { Pre CHO-Free } \\
\text { Standard Diet }\end{array}$ & $\begin{array}{c}\text { CHO-Free } \\
48-72 \mathrm{hr}\end{array}$ & $\Delta$ & $\begin{array}{l}\text { Pre-Fasting } \\
\text { Standard Diet }\end{array}$ & $\begin{array}{l}\text { Fasting } \\
48-72 \mathrm{hr}\end{array}$ & $\Delta$ \\
\hline${ }^{* *}$ Volume $(\mathrm{ml})$ & $3281 \pm 441$ & $3012 \pm 311$ & -269 & $3213 \pm 439$ & $2399 \pm 297^{*}$ & -814 \\
\hline Sodium (mmol) & $223 \pm 21$ & $188 \pm 18$ & -35 & $193 \pm 23$ & $68 \pm 8^{*}$ & -125 \\
\hline Potassium (mmol) & $101 \pm 8$ & $67 \pm 8^{*}$ & -34 & $91 \pm 7$ & $59 \pm 5^{*}$ & -32 \\
\hline Calcium (mg) & $185 \pm 33$ & $151 \pm 16$ & -34 & $198 \pm 26$ & $110 \pm 14^{*}$ & -88 \\
\hline Creatinine (mg) & $1633 \pm 128$ & $1702 \pm 177$ & 69 & $1477 \pm 90$ & $1681 \pm 84^{*}$ & 204 \\
\hline Urea Nitrogen (g) & $13.7 \pm 1.2$ & $12.1 \pm 1.3$ & -1.6 & $12.3 \pm 0.9$ & $10.7 \pm 0.9^{*}$ & -1.6 \\
\hline${ }^{* *}$ Glucose (g) & $23.5 \pm 14.0$ & $0.26 \pm 0.1 \wedge \wedge$ & -23.24 & $29.5 \pm 12.0$ & $0.07 \pm 0.01^{\star}$ & -29.43 \\
\hline
\end{tabular}

Values are means \pm SEM

${ }^{*} \mathrm{P} \leq 0.05$ Standard vs Treatment by Student's t test

$\wedge \wedge \mathrm{P}=0.02$ by Wilcoxon signed rank test

**The average of the 2 "Pre" data sets for volume and glucose, and individual post data set for volume and glucose were published previously [2].

24 Hour collection for Standard (i.e. Control) was from 0800 day 1 to 0800 day 2

24 Hour collection for CHO-Free and Fasting was from 0800 day 4 to 0800 day 5

The creatinine excretion was extraordinarily low for the control diet before fasting, for an unexplained technical reason

Table 3: 24-Hour Urine Data $(\mathrm{n}=7)$

Urine Creatinine (Table 3): The initial quantitative urine creatinine was lower at the beginning of the fasting arm of the study compared to that at the beginning of the $\mathrm{CHO}$-free diet arm. This was a uniform finding, and likely was an assay error. Over the last $24 \mathrm{~h}$ the creatinine had only increased by $69 \mathrm{mg}$ with the CHO-free diet but by $204 \mathrm{mg}$ with fasting. Had the initial creatinine excretions been similar, the slight increase at the end of the study would have been similar.

Other Quantitative Urine Data (Table 3): The mean urine volumes as well as the sodium, potassium and calcium content were similar when the subjects ingested the standard diet on the two different occasions.

Both the $\mathrm{CHO}$-free diet and fasting resulted in a decrease in the urine volume, sodium, potassium, and calcium excretion compared to the standard diet. In general the decrease was greatest when the subjects fasted. During the fast, all of the decreases compared to the standard diet were statistically significant. The potassium decreases were similar and statistically significant in both arms.

Plasma/Serum Data (Table 4): The circulating creatinine, TSH, and $\mathrm{T}_{4}$ concentrations remained unchanged. The $\mathrm{T}_{3}$ decreased in both arms of the study. The HbAlc and glucose data have been published previously and are included for the possible interest of the reader [2].

\begin{tabular}{|c|c|c|c|c|c|c|}
\hline & \multicolumn{6}{|c|}{ Meals } \\
\hline Test & $\begin{array}{c}\text { Pre CHO-Free } \\
\text { (Standard Diet) }\end{array}$ & $\begin{array}{c}\text { Post } \\
\text { CHO-Free }\end{array}$ & $\Delta$ & $\begin{array}{c}\text { Pre Fasting } \\
\text { (Standard Diet) }\end{array}$ & $\begin{array}{c}\text { Post } \\
\text { Fasting }\end{array}$ & $\Delta$ \\
\hline Creatinine $(\mathrm{mg} / \mathrm{dl})$ & $0.8 \pm 0.04$ & $0.9 \pm 0.05$ & $0.1 \pm 0.01$ & $0.8 \pm 0.03$ & $0.9 \pm 0.04$ & $0.1 \pm 0.06$ \\
\hline $\mathrm{TSH}(\mu \mathrm{U} / \mathrm{ml})$ & $1.8 \pm 0.4$ & $2.0 \pm 0.6$ & $0.2 \pm 0.4$ & $2.1 \pm 0.7$ & $1.9 \pm 0.6$ & $-0.2 \pm 0.11$ \\
\hline Free $_{4}(\mu \mathrm{g} / \mathrm{dl})$ & $1.1 \pm 0.03$ & $1.1 \pm 0.03$ & 0 & $1.0 \pm 0.10$ & $1.2 \pm 0.08^{*}$ & $0.2 \pm 0.07$ \\
\hline Total T $_{3}(\mathrm{ng} / \mathrm{dl})$ & $111 \pm 5$ & $94 \pm 5^{*}$ & $-17 \pm 5$ & $113 \pm 8$ & $93 \pm 5^{*}$ & $-20 \pm 6$ \\
\hline $\mathrm{HbAl}^{*}(\%)$ & $7.9 \pm 0.4$ & $7.8 \pm 0.5$ & $-0.1 \pm 0.1$ & $8.1 \pm 0.5$ & $7.9 \pm 0.5$ & $-0.2 \pm 0.1$ \\
\hline${ }^{*}$ Glucose $(\mathrm{mg} / \mathrm{dl})$ & $188 \pm 22$ & $149 \pm 14^{*}$ & $-39 \pm 12$ & $204 \pm 25$ & $114 \pm 11^{*}$ & $-90 \pm 23$ \\
\hline
\end{tabular}

Values are means \pm SEM, Standard Diet $=$ Control ( $55 \%$ CHO $15 \%$ protein $30 \%$ fat)

${ }^{*} \mathrm{P}<0.05$ Standard vs Treatment by Student's $\mathrm{t}$ test

$\Delta=$ Post minus Pre value

**Average of the data for Pre CHO-free and Pre Fasting Standard data for volume and glucose, and individual data for post volume and glucose published previously [2].

Abbreviations: TSH=Thyroid-stimulating hormone; $\mathrm{T}_{4}=$ thyroxine; $\mathrm{T}_{3}=$ triiodothyronine; HbAlc=Hemoglobin Alc

Table 4: Plasma/Serum Data $(n=7)$

\section{Discussion}

In people without diabetes, the weight loss of short-term fasting $(\sim 1 \mathrm{~kg} /$ day $)$ was reportedly reproduced by a CHO-free diet $[1,12]$. It was associated in both metabolic states by a similar sodium-induced diuresis. Addition of dietary CHO resulted in prompt sodium retention. Diuresis-associated weight loss was greatest during the first $24 \mathrm{~h}$, and generally lasted only 3-4 days. It was 
associated with little change in potassium excretion, indicating little loss of non-fat body mass [12]. Later, this was documented by determination of total body potassium [13]. In contrast, in the present study, when the CHO-free diet was ingested, weight loss was linear and only $0.5 \mathrm{~kg} /$ day. This was associated with little change in urine volume or sodium excretion. A much greater weight loss occurred with fasting ( $1 \mathrm{~kg} /$ day). The majority occurred during the first $24 \mathrm{~h}$, likely associated with a major initial sodium diuresis. Urine volume decreased $25 \%$ and sodium excretion decreased $65 \%$ by the last $24 \mathrm{~h}$. Thus, these results were similar to those obtained previously by others [12]. Initially a major but similar glucosuria was present. It essentially disappeared by the last $24 \mathrm{~h}[2]$, which could complicate interpretation of the data.

The RMR, as well as body weight, at the initiation of each arm of the study was similar when the subjects ingested a mixed diet, although the data were obtained weeks apart. At the end of the study the RMR had decreased by $11 \%$ with the $\mathrm{CHO}$-free diet and $16 \%$ with fasting, a statistically non-significant difference. We are not aware of comparative RMR data in people with T2DM between a short-term fast and a low or CHO-free diet. Thus, whether the current data are typical of the subjects with T2DM in general, remains to be determined. In contrast to the modest decrease noted in these men with T2DM, in normal young men and women, an increase in RMR has been reported with short-term fasting or no change after fasting for 7 days [14-18]. With a $\mathrm{CHO}$-free diet, Bergstrom et al reported a decrease in RMR in fit young men [19]. However, others reported no change in normal subjects [20-22].

In subjects without diabetes, many authors have reported that a CHO-free or a very low CHO diet, or fasting, induced a decrease in plasma $\mathrm{T}_{3}$ [22-27]. As reported by the current Senior Author, the decrease in $\mathrm{T}_{3}$ can be observed within $8 \mathrm{~h}$ when CHO-free meals are ingested [28]. In our subjects, a decrease in total $\mathrm{T}_{3}$ was present and was similar when ingesting the low-CHO diet or fasting.

To our knowledge, there are only limited nRQ data obtained in normal subjects ingesting a CHO-free diet. In 7 males the calculated fuel mixture being oxidized was $12 \% \mathrm{CHO}, 88 \%$ fat after 4 days [20]; similar data were reported in 6 males [19]. Thus, when CHO was not available, fuel consumption was essentially from fat. With fasting, a low CHO: high fat oxidation ratio ( $10 \%$ CHO: $90 \%$ fat) has been reported frequently [14-17,25]. Our data indicate CHO still provided a significant component to the oxidized fuel and was similar in each arm. For unknown reasons, these subjects with T2DM had not completely adapted to a typical fat-derived fuel mixture. Circulating glucose concentrations also were higher than in normals [2]. Whether this could result in a greater glucose production rate is a consideration.

In normal subjects, the gluconeogenesis rate reportedly remains unchanged with a short-term $\mathrm{CHO}$-free diet or with fasting $[29,30]$. The predominant change in glucose production is due to a change in the net rate of glycogen oxidation. In the present study, the net glucose utilization (glycogen-dependent glucose oxidized) was estimated by two different methods. The first was based on the RMR and nRQ data, the second on the 24-h urinary potassium excretion. Results were similar. Traditionally oxidation of liver glycogen as fuel is considered to occur during the first 1-2 days of fasting. If glycogen is depleted, the only source of CHO fuel is through recycling of glucose via the Cori cycle, amino acids from protein, plus a small amount derived from fat. In normal people, needle biopsy data indicated that liver glycogen was indeed rapidly ( $24 \mathrm{~h}$ ) reduced during short-term fasting or ingestion of a CHO-free diet [31]. However, it was still present and became stable, but at a low level, and was not re-accumulated until CHO was ingested [31]. Similar data were obtained by others later using NMR spectroscopy to quantify liver glycogen. This was compared to the overall glucose production rate [32]. There was essentially no net glycogenolysis from $46-64 \mathrm{~h}$ of fasting, and $96 \%$ of glucose production was due to gluconeogenesis. Owen et al also reported that oxidation of $\mathrm{CHO}$ from glycogen was undetectable after 2 days of fasting in obese subjects, some with T2DM [27]. However, other indirect data suggest that considerable glycogen is still present in subjects with T2DM after 64-72 h of fasting and can be a source of fuel, if gluconeogenesis is impaired [32,33]. Glycogen may actually be increased after a 72-h fast [34]. In addition, inhibition of gluconeogenesis by ethanol administration did not result in hypoglycemia [35], which would be expected if glycogen was not present and mobilizable as fuel [33]. The amount of glucose released by glucagon injection also was reported to be much greater in subjects with T2DM after a 3 day fast [34]. Our data based on RMR and nRQ calculations, also are compatible with liver glycogen being increased and mobilizable as fuel in these subjects. The source of excessive glycogen stores and the mechanism by which a relatively high CHO utilization occurs when fasting or not ingesting CHO remains unexplained. Our data indicate it cannot be due to an accelerated metabolism of protein.

Circulating urea nitrogen concentrations remained unchanged following mixed meals, $\mathrm{CHO}$-free meals, or with fasting. Also, the concentration did not vary throughout $24 \mathrm{~h}$, indicating lack of a meal-related effect of ingested protein, and lack of a circadian rhythm. With fasting it remained stable even though the urinary excretion decreased, suggesting a strong intrinsic system for regulating the circulating urea and presumably total body protein turnover. We are not aware of comparative data. In normal subjects with short-term fasting, urea nitrogen excretion reportedly remains the same as when ingesting mixed meals or increases modestly [36,37]. However, other authors reported a decrease [32,38,39]. After $72 \mathrm{~h}$ on a CHO-free diet, urine nitrogen excretion reportedly doubled in normal subjects [40]. Also, an increase was reported in normal subjects ingesting a CHO-free diet over 10 days [41]. The present results in subjects with T2DM are different. Urea nitrogen excretion was similar following mixed meals on 2 different occasions or with $\mathrm{CHO}$-free meals, and was only modestly lower with fasting. Thus, the amount of protein used for fuel was similar regardless of the dietary changes. Creatinine excretion also was similar, compatible with a stable utilization of creatine by muscle, and maintenance of skeletal mass. If so, the excreted urea was the result of oxidation of non-structural proteins in the 
so-called labile protein pool [25]. Maintenance of skeletal muscle mass with short-term fasting also has been observed in normal subjects [27].

\section{Conclusion}

We suggest that glucose sensing provides a mechanism for assuring an adequate type and amount of fuel for the brain and other organs under all possible variations in macronutrient ingestion, as well as when exogenous fuel is lacking. In the present study, in one case the fuel supply was exogenous while in the other it was endogenous, indicating the ability of the body to similarly regulate the mixture of fuels being oxidized regardless of source.

The study strengths are: a well-controlled observational study with 2 different methods of inducing a dietary carbohydrate deficiency, the metabolic stability of the subjects, and a separate control diet for each arm of the study. The study limitations are: the relatively small number of subjects and males only; thus the results may or may not be representative of subjects with T2DM, in general.

We were not able to find contemporary data in subjects without diabetes ingesting a carbohydrate-free diet to compare to our study. It is known that certain indigenous peoples (Greenland Eskimos, Central Plains Indians), explorers in the early 20th century, etc. were able to exist for long periods of time on a carbohydrate-free diet [42-44]. These were presumably normal healthy adults. However, detailed quantitative measurements of fuel metabolism are not available for these subjects.

While not directly related to the present study, there is a literature regarding the effect of high- or low-carbohydrate diets in normal subjects interested in improving athletic performance.

Since the 1960s, when techniques for muscle biopsies were popularized by Bergstrom et al, high muscle glycogen concentration has been associated with enhanced physical performance $[19,45]$. High carbohydrate diets, and/or carbohydrate loading are techniques used to increase muscle glycogen concentration.

An observation by Pernow and Saltin suggested that some "heavy exercise" was possible following reduction of muscle glycogen, provided that an adequate supply of non-esterified fatty acids (NEFAs) was available to the muscle [46]. Subsequently Phinney et al. reported that chronic ketosis, induced by dietary carbohydrate restriction, was not deleterious to physical performance $[22,47]$. Current literature exists in support of enhanced exercise performance with both high-carbohydrate and ketogenic diets (for example, [48-51]).

\section{Acknowledgments}

The authors thank our volunteers with type 2 diabetes, the staffs of the SDTU and the Clinical Chemistry Laboratory, Heidi Hoover, MS, RD, Research Dietitian and Linda Hartich, MT, Laboratory Technologist. Without the help and dedication of these individuals, the current studies would not have been possible.

\section{Funding}

Supported in part by Funds from the Department of Veterans Affairs. This material is the result of work supported with resources and the use of facilities at the Minneapolis VA Health Care System. The Department of Veterans Affairs had no involvement in the study design, the collection, analysis and interpretation of data, in the writing of the manuscript or in the decision to submit the manuscript for publication.

\section{Author Contributions}

RMA applied for and obtained IRB approval for the study, recruited and enrolled the subjects, determined the randomization schedule, obtained the blood specimens, performed the majority of the indirect calorimetry, and contributed to the data analysis. RMA was a Fellow in Endocrinology when these studies were done. His present address is: Park Nicollet Health Care System, 3800 Park Nicollet Blvd., St. Louis Park, MN 55416, USA. FQN and MCG obtained the funding, formulated and designed the study, performed the final analysis of the data and wrote the final manuscript. FQN is the guarantor of this work and, as such, had full access to all the data in the study and takes responsibility for the integrity of the data and the accuracy of the data analysis.

\section{References}

1. Bloom WL, Mitchell W (1960) Salt excretion of fasting patients. Arch intern med 106: 321-6.

2. Nuttall FQ, Almokayyad RM, Gannon MC (2015) Comparison of a carbohydrate-free diet vs. Fasting on plasma glucose, insulin and glucagon in type 2 diabetes. Metabolism 64: 253-62.

3. Nuttall FQ, Almokayyad RM, Gannon MC (2016) The ghrelin and leptin responses to short-term starvation vs a carbohydrate-free diet in men with type 2 diabetes; a controlled, cross-over design study. Nutr Metab 13: 47.

4. American Diabetes A (2010) Standards of medical care in diabetes--2010. Diabetes care 33: S11-61.

5. Taylor HL, Henschel A, Mickelsen O, Keys A (1954) Some effects of acute starvation with hard work on body weight, body fluids and metabolism. J Appl physiol 6: $613-23$. 
6. Patrick J (1977) Assessment of body potassium stores. Kidney int 11: 476-90.

7. Kreitzman SN, Coxon AY, Szaz KF (1992) Glycogen storage: Illusions of easy weight loss, excessive weight regain, and distortions in estimates of body composition. Am J Clin Nutr 56: 292S-3.

8. Poehlman ET, Horton ES (1999) Energy needs: Assessment and requirements in humans. In: Modern nutrition in health and disease $9^{\text {th }}$ Edn. Baltimore: Lippincott Williams \& Wilkins.

9. White A, Handler P, Smith E (1968) Principles of biochemistry $4^{\text {th }}$ Edn. McGraw-Hill, New York.

10. Frayn KN (1983) Calculation of substrate oxidation rates in vivo from gaseous exchange. J Appl Physiol Respir Environ Exerc Physiol 55: 628-34.

11. Gannon MC (1991) A computer program to calculate the rate of appearance of glucose in the peripheral circulation following infusion of labeled glucose. University of Minnesota, Minneapolis, USA.

12. Bloom WL, Azar GJ (1963) Similarities of carbohydrate deficiency and fasting. I. Weight loss, electrolyte excretion, and fatigue. Arch Intern Med 112: 333-7.

13. Benoit FL, Martin, RL,Watten RH (1965) Changes in body composition during weight reduction in obesity. Balance studies comparing effects of fasting and a ketogenic diet. Ann Intern Med 63: 604-12.

14. Webber J, Macdonald IA (1994) The cardiovascular, metabolic and hormonal changes accompanying acute starvation in men and women. Br J Nutr 71: 437-47.

15. Mansell PI, Macdonald IA (1990) The effect of starvation on insulin-induced glucose disposal and thermogenesis in humans. Metabolism 39: 502-10.

16. Mansell PI, Fellows IW, Macdonald IA (1990) Enhanced thermogenic response to epinephrine after 48-h starvation in humans. Am J Physiol 258: R87-93.

17. Zauner C, Schneeweiss B, Kranz A, Madl C, Ratheiser K, et al. (2000) Resting energy expenditure in short-term starvation is increased as a result of an increase in serum norepinephrine. Am J Clin Nutr 71: 1511-5.

18. Nair KS, Halliday D, Ford GC, Garrow JS (1989) Effect of triiodothyronine on leucine kinetics, metabolic rate, glucose concentration and insulin secretion rate during two weeks of fasting in obese women. Int J Obes 13: 487-96.

19. Bergstrom J, Hermansen L, Hultman E, Saltin B (1967) Diet, muscle glycogen and physical performance. Acta Physiol Scand 71: 140-50.

20. Galbo H, Holst JJ, Christensen NJ (1979) The effect of different diets and of insulin on the hormonal response to prolonged exercise. Acta Physiol Scand 107: 19-32.

21. Bisschop PH, Sauerwein HP, Endert E, Romijn JA (2001) Isocaloric carbohydrate deprivation induces protein catabolism despite a low $\mathrm{T}_{3}$-syndrome in healthy men. Clin Endocrinol 54: 75-80.

22. Phinney SD, Bistrian BR, Wolfe RR, Blackburn GL (1983) The human metabolic response to chronic ketosis without caloric restriction: Physical and biochemical adaptation. Metabolism 32: 757-68.

23. Otten MH, Hennemann G, Docter R, Visser TJ (1980) The role of dietary fat in peripheral thyroid hormone metabolism. Metabolism 29: 930-5.

24. Fery F, Bourdoux P, Christophe J, Balasse EO (1982) Hormonal and metabolic changes induced by an isocaloric isoproteinic ketogenic diet in healthy subjects. Diabete Metab 8: 299-305.

25. Nair KS, Woolf PD, Welle SL, Matthews DE (1987) Leucine, glucose, and energy metabolism after 3 days of fasting in healthy human subjects. Am J Clin Nutr 46: 557-62.

26. Beer SF, Bircham PM, Bloom SR, Clark PM, Hales, CN, et al. (1989) The effect of a 72-h fast on plasma levels of pituitary, adrenal, thyroid, pancreatic and gastrointestinal hormones in healthy men and women. J Endocrinol 120: 337-50.

27. Owen OE, Smalley KJ, D’Alessio DA, Mozzoli MA, Dawson EK (1998) Protein, fat, and carbohydrate requirements during starvation: Anaplerosis and cataplerosis. Am J Clin Nutr 68: 12-34.

28. Slag MF, Shafer RB, Elson MK, Nuttall FQ (1981) Rapid decrements in $T_{4}$ to $T_{3}$ conversion with high fat diets. Clini Res 29: 709A.

29. Bisschop PH, Pereira Arias AM, Ackermans MT, Endert E, Pijl H, et al. (2000) The effects of carbohydrate variation in isocaloric diets on glycogenolysis and gluconeogenesis in healthy men. J Clin Endocrinol Metab 85: 1963-7.

30. Nuttall FQ, Ngo A, Gannon MC (2008) Regulation of hepatic glucose production and the role of gluconeogenesis in humans: Is the rate of gluconeogenesis constant? Diabetes Metab Res Rev 24: 438-58.

31. Nilsson LH, Hultman E (1973) Liver glycogen in man--the effect of total starvation or a carbohydrate-poor diet followed by carbohydrate refeeding. Scand J Clin Lab Invest 32: 325-30.

32. Rothman DL, Magnusson I, Katz, LD, Shulman, RG, Shulman GI (1991) Quantitation of hepatic glycogenolysis and gluconeogenesis in fasting humans with ${ }^{13} \mathrm{C}$ NMR. Science 254: 573-6.

33. Arky RA, Freinkel N (1966) Alcohol hypoglycemia. V. Alcohol infusion to test gluconeogenesis in starvation, with special reference to obesity. N Engl J Med 274: $426-33$

34. Clore JN, Post EP, Bailey DJ, Nestler JE, Blackard WG (1992) Evidence for increased liver glycogen in patients with noninsulin-dependent diabetes mellitus after a 3-day fast. J Clin Endocrinol Metab 74: 660-6.

35. Clore JN, Blackard WG (1994) Suppression of gluconeogenesis after a 3-day fast does not deplete liver glycogen in patients with NIDDM. Diabetes 43: 256-62.

36. Cahill GF, Herrera MG, Morgan AP, Soeldner JS, Steinke J, et al. (1966) Hormone-fuel interrelationships during fasting. J Clin Invest 45: 1751-69.

37. Henry CJ, Rivers JP, Payne PR (1988) Protein and energy metabolism in starvation reconsidered. Eur J Clin Nutr 42: 543-9.

38. Deuel HJ, Gulick M, Butts JS (1932) Studies on ketosis II. The comparative ketolytic action of glucose, galactose, fructose, and sucrose. J Biol Chem 98: 333-51.

39. Marliss EB, Aoki TT, Unger RH, Soeldner JS, Cahill GF (1970) Glucagon levels and metabolic effects in fasting man. J Clin Invest 49: 2256-70.

40. Azar GJ, Bloom WL (1963) Similarities of carbohydrate deficiency and fasting II. Ketones, nonesterified fatty acids and nitrogen excretion. Arch Intern Med 112: $338-43$

41. Bisschop PH, De Sain-Van Der Velden MG, Stellaard F, Kuipers F, Meijer AJ, et al. (2003) Dietary carbohydrate deprivation increases 24-hour nitrogen excretion without affecting postabsorptive hepatic or whole body protein metabolism in healthy men. J Clin Endocrinol Metab 88: 3801-5.

42. McClellan WS, Du Bois EF (1930) LV. Prolonged meat diets with a study of kidney function and ketosis. J Biol Chem 45: 651-68.

43. Stefansson V (1944) Pemmican. Mil Sur 95: 89-98.

44. Stefansson V (1960) The fat of the land (Third Printing 1961 Edn). New York: The Macmillan Company. 
45. Hermansen L, Hultman E, Saltin B (1967) Muscle glycogen during prolonged severe exercise. Acta Physiol Scand, 71: 129-39.

46. Pernow B, Saltin B (1971) Availability of substrates and capacity for prolonged heavy exercise in man. J Appl Physiol 31: 416-22.

47. Phinney SD, Bistrian BR, Evans WJ, Gervino E, Blackburn GL (1983) The human metabolic response to chronic ketosis without caloric restriction: Preservation of submaximal exercise capability with reduced carbohydrate oxidation. Metabolism 32: 769-76.

48. Volek JS, Noakes T, Phinney SD (2015) Rethinking fat as a fuel for endurance exercise. Eur J Sport Sci 15: 13-20.

49. Burke LM (2015) Re-examining high-fat diets for sports performance: Did we call the 'nail in the coffin' too soon? Sports Med 45: S33-49.

50. Burke LM, van Loon LJC, Hawley JA (2017) Postexercise muscle glycogen resynthesis in humans. J Appl Physiol 122: $1055-67$.

51. McSwiney FT, Wardrop B, Hyde PN, Lafountain RA, Volek JS, et al. (2018) Keto-adaptation enhances exercise performance and body composition responses to training in endurance athletes. Metabolism 81:25-34.

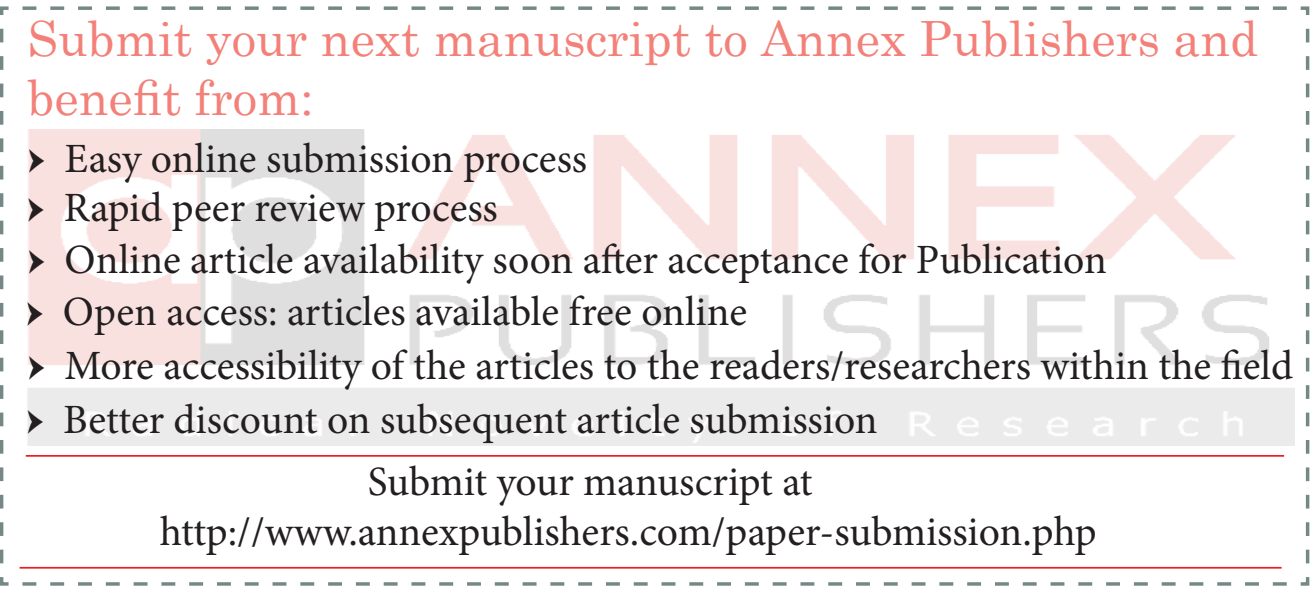

